\title{
Study on the Strategies for Developing Green Economy In Vietnam
}

\author{
MA.Pham Huy Thong ${ }^{1}$, MA. Pham Thanh Trung ${ }^{2}$ \\ ${ }^{1,2,}$ College of Marxism studies of Hunan University, Changsha, Hunan, PR China (410082)
}

\begin{abstract}
Green Economy is an economy towards the improvement of people's lives and social assets, minimizing environmental hazards and resource scarcity. So, for Vietnam, transition of the mode of development towards the development of "Green Economy" is a new approach.
\end{abstract}

Keywords: Environment, Green Economy, People, Natural Resources, Vietnam

Date of Submission: 08 November 2016

Date of Accepted: 18 November 2016

\section{INTRODUCTION}

Recently, mankind has coped with the new crisis, of which climate crisis / climate change is the most important. In this context, the green economy is said to be the most viable path to face with climate change and remain sustainable development. Vietnam has issued the National Strategy for Green Growth and shall deploy it nationwide in next time. Green growth not only creates the opportunity for Vietnam to implement the restructuring of the economy with rapid and sustainable development of the country but also creates many difficulties and challenges in many ways on the path of integration with the global green trend.

\section{GREEN ECONOMY - GLOBALLY SUSTAINABLE GROWTH PATH}

The idea of "green economy" was initiated by the United Nation Environment Program (UNEP) in 2008. Many organizations and international forums have focused on discussion of this topic. Recently, it has been highlighted at the Conference on Sustainable Development 2012 (Rio + 20) in Brazil. Awareness of the concept of "green economy" so far has not really clear with many different interpretations and names. Despite of it, all names have common views and perceptions which are: Green Economy, Social Development and Environmental Protection are the three foundations of sustainable development and are the best choice for the sustainable development of nations. This is an environmentally friendly economy based on clean energy, reduction of greenhouse gas emissions to mitigate climate change; it is the economy of the growth in depth with less fuel loss, technological innovation, promotion of ecological industries; towards sustainable growth, poverty reduction and equitable development.

Overall, "there are two main ways for the transition to a green economy model: Developed countries with abundant finance, human resources and technology can move to a green economy via investment, development of new areas of the economy for social development and environmental sustainability"[1]. Meanwhile, the emerging economies shall have to spend more costs and time to adjust gradually the traditional economy to become more environmentally friendly. Currently, many countries are pioneers in building the green economy (such as the USA, Germany, Britain, France, Japan, Korea) with main measures such as increase of investment and expenditures in the areas of promoting the development of green economy: energy, transport, construction, agriculture, tourism, culture, waste treatment..., raising awareness about the challenges of traditional economies as well as opportunities and advantages of green economy and sustainable development, improvement of the management capacity of State agencies and investment in skills training for the workforce who serve green economy, expansion of the market for the environmentally friendly products and services; reduction of Government's expenditure in the areas of un-renewable natural resources; development of a network of organizations and agencies to help the transition to the green economy model, setting up a law system and policies that promote the green economy; using taxes, fees to minimize negative impacts on the environment (mechanism for greenhouse gas emission; tariffs and charges for the use of inefficient energy, taxes of ownership and use of traffic vehicles ..., the negative effects on the environment and life is included in order to calculate prices, costs of goods and services, thereby creating conditions for marketization and gradually transition to production of environmentally friendly goods and services), strengthening international cooperation . 


\section{POLICIES ON THE DEVELOPMENT OF GREEN ECONOMY IN VIETNAM}

In recent years, Vietnam's economy has achieved significant achievements without sustainable development. The growth of economy in Viet Nam still relies heavily on the exploitation of natural resources with low labor productivity, manufacturing technology and consumption also take advantage of a lot of energy, materials with many waste emission. Many natural resources are exploited exhaustively, wastefully and inefficiently. The natural environment in many places is seriously destructed, polluted and degraded at an alarming rate ... Thus, access to and forming a green economy is the urgent requirement for realization of sustainable development of the economy, poverty alleviation. From awareness of the significance of this opportunity and for the country's development and integration with the international trend, the Government has issued these strategically important documents such as the Decision No. 2139 / QD-TTg dated 05/12/2011 on approving the National Strategy on climate change, Decision No. 432 / QD-TTg dated 12/4/2012 on approving the Sustainable Development Strategy for Vietnam in the period of 2011-2020, Decision No. 1393 / QD-TTg dated 25/9/2012 on approving the National Strategy for Green Growth in the period of 2011-2020 and vision to 2050, Decision No. 339 / QD-TTg dated 19/2/2013 on approving the general scheme of economic restructuring associated with growth model towards improving quality, efficiency and competitiveness in the period of 20132020. Basically, the main content of these documents is that the green economy in Vietnam must be considered in term of economic, environmental and social management perspectives.

First, from the economic perspective, the opinion on the green economy of Viet Nam, broadly speaking, is a way to promote sustainable economic development based on sustainable factors. This process must take place harmonically and reasonably in consistence with the conditions and circumstances in Vietnam that is to be adjusted gradually so that traditional economy shall become more environmentally friendly, reduce the reliance on unsustainable factors (such as limited natural resources) and increase the sustainable factors (geopolitical position, knowledge, technology science, consumption, investment, exports, landscape, culture, traditions, people ...) for development. In other words, economic restructuring shall shift towards narrowing the area of "brown economy", expanding the area of "green economy" on the basis of the potential difference, outstanding opportunity and comparative advantage.

Second, from the perspective of environmental management, economic growth under the model of green economy must ensure the balance between fast economic growth and economical and efficient use of natural resources and environmental protection, especially in the process of promoting industrialization and modernization via the focus on development and innovation of production technology towards environmentally friendly economy and low carbon, construction and implementation of a roadmap to limit the use of fossil energy, enhancement of the State management of natural resources, environmental protection, waste treatment, coping with climate change ...Third, from the perspective of social management, the green economy is the process of linkage between economic growth and social progress and justice. This is a consistent criterion because Vietnam's economy is the socialist-oriented market economy. Vietnam is in the process of ensuring economic growth associated with poverty alleviation, social progress and social justice, implementing the new rural construction, improving the system of social security and social welfare ... At a higher level, the access to a green economy means that Vietnam must implement lifestyle greening and promote sustainable consumption.

\section{GREEN ECONOMY: OPPORTUNITIES AND CHALLENGES FOR VIETNAM}

\section{Opportunities}

First, Vietnam has a comparative advantage in natural conditions, natural resources position, population and society - a good prerequisite for the green economy. Vietnam has a great potential to:

+ Develop agriculture and to become a key figure, with "green power" in ensuring food security for the world in the future.

+ Develop renewable energy (solar energy, wind energy, ocean energy, hydro energy, biomass ...) - the most important factor in the era of energy- climate in the coming time.

+ Diversify the economy based on the diversity of terrain, climate and natural resources / ecosystem to exploit the strengths of natural capital.

+ Develop tourism, especially ecotourism with many diversified \&unique natural scenery.

+ Develop natural capital with high biological diversity $\left(16^{\text {th }}\right.$ ranked in the world), "the forest coverage rate is approximately 50\% at present with the northern mountains and forests and Truong Son mountain range running along the country, ensuring ecosystem services for economic-social-cultural development, water security, providing residences, maintaining the local culture, controlling natural disasters such as floods, landslides, erosion and soil deposition" [1].

Second, Vietnam's economy has continued to grow in recent years which have created internal forces for a new development trend. The issues on environmental pollution and natural resource depletion in recent years have awakened the leaders and people to support new development trend- a green economy - to create the high consensus of the society on elimination of "brown economy". 
Third, the workforce of Vietnam are at the stage of "golden population" with traditionally hardworking, simple life in harmony with nature and traditional oriental culture, capability of mastering quickly science - technology and management skills for green workforce development.

Fourth, Vietnam has a stable social \& political situation with more and more expanded international relations, favorable legal environment, mechanisms and policies towards promotion of "economic restructuring associated with growth model "and see it as the top task of socio-economic development strategies in the period of 2016-2020.

Fifth, Vietnam has and will receive the active support of the international community (UNDP, World Bank, Denmark, Sweden, Germany, Japan, France, United States ...) in response with climate change in particular and green growth in general.

All these positive factors are converging into a springboard for Vietnam to build a green economy and confirm that "green growth" is the optimal plan for sustainable development for sustainable growth, hunger eradication and poverty reduction of the country.

\section{Difficulties and challenges}

First, awareness and overall development level is still low, lagging behind many countries after years of protracted war with large disasters which takes much time and substantial resources to overcome.

Second, the legal system is in transition, not uniform, not very consistent with the trend of globalization and green growth; organizational system, management apparatus are divided which are not suitable for the development of links in the integration of the country.

Third, effectiveness of resource utilization is low and wasteful, natural resources (natural capital), especially biological resources are severely degraded, non-renewable resources are being exploited exhaustedly.

Fourth, "the production technology is backward with much energy consumption, low-quality products, waste emission, environmental pollution and degradation, increase of GHG emissions" [1].

Fifth, the "brown" economic sector is a large proportion of the economy.

Sixth, the clean energy industries such as nuclear energy, wind energy, sun energy, biomass, geothermal energy are underdeveloped. In addition, many agencies supporting, solving environmental problems, environmental services, industrial recycling ... are weak.

Seventh, Vietnam is one of the very few countries which is most severely affected by climate change, vulnerability to more and more increasing disasters and climate impact.

Eighth, lifestyles and consumption style of a majority of people are still wasteful with destruction of natural resources, not friendly and harmonious with nature.

\section{MAIN SOLUTIONS}

Transition to a green economy requires Vietnam to implement total solutions such as propaganda, shift of economic structure, construction of a legal environment, promotion of technological innovation, the development of clean energy resources ... The scope of this article emphasizes resource solutions which requires mobilization, focus and investment in resources and financial mechanisms in an appropriate manner. This is the most important solution in the current context. It is forecasted that in the next time, the world economy is still very difficult and complex unpredictably and will affect the elements of the productive forces, especially the capital. It is necessary to combine harmonically the attraction of resources and the shift of input structure in the direction of decreasing the rate of physical factors and the workforce, then increasing the role of general productivity factors on the basis of rapid development of high quality human resources associated with the application of scientific and technological advance. Meanwhile, the distribution of resources for the growth must follow signals and principles of the market.

Moreover, the investment method to promote the development of the green economy must take the public finance as leverage so that private capital shall account for a major role in later stages. Pilot application of specific policies is made for some areas and localities with potentials and opportunities to meet the requirements for green development. On this basis, experience shall be drawn to create resources and motivation to apply it on a larger scale. Vietnam also needs to invest in economic sectors which can promote the comparative advantages of the country, emphasizing the research and development of cultural industry - this is a typical green economy that South Korea and China is building, invest in development of high quality human resources to build knowledge-based economies, develop the innovation of production technology towards environmental friendliness, enhancement of management capacity and supervision of state authorities...Vietnam also needs to take advantage of the financial support and techniques from the international community for the green economy. At the same time, we need to develop mechanisms and incentives to encourage maximally domestic and foreign enterprises to invest in development of the areas of the green economy. Besides, we should integrate the mobilization of investment resources for green development with the socio-economic planning, development planning of sectors, regions and localities, strengthen State management, effective exploitation with the right purpose, avoid negative impacts and loss in the National Target Program to cope with climate 
change ... Sustainable Development Support Fund should be established based on the experience of other countries. Preferential policies should be issued to develop financial and credit operations related to environmental protection, including the development of environmentally friendly science and technology.

\section{CONCLUSION}

Green economy - sustainable development path in the context of climate change - is becoming an advanced development model which is aimed by many countries in the world and it is considered as one of solutions to help us scape the current recession. To promote strongly the process of economic restructuring with the rapid and sustainable development, Vietnam has promulgated the National Strategy for Green Growth in the period of 2011- 2020 with a vision to 2050 and shall deploy it on a national scale in the next time. Besides these specific challenges, Vietnam also have many opportunities to implement strategies and integrate with the green economy of the world.

\section{REFERENCES}

[1]. Truong Quang Hoc, 2013b. Research and Development of Ecosystem Based Approach in Viet Nam. Regional Workshop "Mainstreaming Ecosystem Based Approach to Climate Change into Biodiversity Conservation Planning". Co-organized by ADB, MONRE, WWF and SIDA. Ha Noi, 15-16th October 2013, Pg25,28.

[2]. Truong Quang Hoc (2001). Dictionary of Biodiversity and Sustainable Development.

[3]. Millennium Ecosystem Assessment (MEA), 2005. Ecosystems and Human Well-being. MEA, Malaysia and United States.

[4]. UNEP., 2011. Green Economy: Towards a Green Economy: Pathway to Sustainable Development and Poverty Eradication. Geneve: UNEP.

[5]. WB, 2010a. World Development Report: Development and Climate Change. Washington DC: World Bank.

[6]. WB, 2010b. Convenient Solution to an Inconvenient Truth: Ecosystem Based Approaches to Climate Change. World Bank.

[7]. WHO,. (2012). "Preventing disease through clean environment: assess the rate suffered diseases caused by the environment. 【Online】 Available: http://en.dangcongsan.vn/.

[8]. WHO,.(2016). Environment and health in developing countries, [Online] Available: http://www.who.int/heli/risks/ehindevcoun/en/. 